\title{
Show me the money: Conspiracy theories and distant wealth
}

\author{
Theodoros Rakopoulos, University of Oslo
}

\begin{abstract}
This article explores the meanings of imagined, secret and hidden wealth that followers of conspiracy theory account in different sides of the moral compass: as bad and good. Conspiracy theory, a strand of intellectual practice exacerbated by the recent crisis in Greece, calls for exploring hidden assets. Their mirror-image, transparency, becomes central in the understanding of wealth in this conundrum. Through the story of Artemis Sorras -a self-proclaimed trillioner-, and conspiracist publishers in Greece, I examine the centrality of (un)accountable wealth in imaginations of people's present and pasts -and the ways they come to terms with crisis. I explore narratives of wealth in conspiracist discourse trajectories, showing how wealth, can play a role in imagined allegiances and political practices, as well as ways people conceptualise crises. Notions of accountability and secrecy are central to their (and ours) understandings of wealth - and are laden with contradictions, according to diverse moral paths.
\end{abstract}

\section{Introduction: suspicion, transparency, wealth}

This essay looks at ways we can assess how followers of "conspiracy theories" understand histories and futurities of potential wealth. I look into two ethnographic cases of coming to terms with wealth, one contemporary and one historical. Firstly, I explore the case of a conspiracy theorist that claims he owns "distant" wealth, set for 
the salvation of Greeks; secondly, I examine some Greek perceptions of a classic conspiratorial book, the Protocols of the Elders of Zion, a "leaked" pseudo-document that "exposes" "Jews" for influencing governments through their assumed wealth. While the first is viewed as positive wealth, the latter is negative. I argue that these alternative truths have in common a sense of distance for wealth that is nonaccessible, hidden. This indigenous conceptualization of wealth is unsettling of our common, established understanding of the phenomenon - it poses as an alternative reading of hidden wealth.

The very idea of alternative knowledge seems to be more central in world events than ever. A reign of "alternative facts" is coupling, as an ideological and aesthetical counterpart, the ascendance of Donald Trump, the dizzyingly wealthy and controversial US president. Trump's chief strategist is Steve Bannon, an ex-financier that turned journalist and director of "anti-establishment" documentaries where conspiracy theory reigns supreme. Exploring wealth narratives that coincide with antiSemitism and counterbalance modern capitalism, we might come across some interesting reconceptualisations of what it means to be accountable for an imagined, yet ostensibly material, wealth.

"Conspiracist" trends during my fieldwork in Greece ${ }^{1}$ in $2016-16$ included stories as diverse as chem-trail narratives, UFO abductions, analyses on the "ancient creed" of Greek blood, and the idea that secretive Reptilian human-like monsters control the European Union. They also included "positive conspiracies", narratives concerned with "saving Greece" from austerity and crisis - often through the usage of material wealth assets. Such positive narratives comprise the alliance of a secret club, the Epsilon forces, that conspire against Greece's enemies, and an associated wealth fund that would invest $600 \mathrm{bn} €$ towards buying off the country's debt ${ }^{2}$. One might 
expect that such promise could in theory operate more convincingly showing some proof for the existence of such wealth. Actually, it is in fact proving to be efficient precisely because the money seem hidden and secret, distant from a reality that conspiracy theorists deem obscured.

An analytical trend that started in US political science and still resonates, asserts conspiracy theories develop within a political culture of paranoia, bred in secrecy (Hofstadter 1964 [2008]). Paranoia is here defined as a cultural force forging political personhood as feeling persecuted - and identified with the "emotional animus" of the Right (Hofstadter 2008: xxiii). The main undertone proceeds from the premise that conspiracy theory is rooted in irrationality. The chief feature attributed to it is its capacity to provide intellectual convenience in an increasingly complex world (Taguieff 2010). As shown below, in coming to terms with history, conspiracy theorists often follow anti-Semitic and anti-masonic strands, attacking alleged wealthamassing agents. This way, they provide an anti-establishment response to the complexity of our epoch of globalized capital, where everything, including wealth, is at once transparent and indecipherable (Taguieff 2015).

\section{Bombs, Money, and Epsilon}

On the $23^{\text {rd }}$ of October 2015, a few days before the anti-fascist OXI ("no") annual national holiday celebrations of Greece, two bombs went off in the Peloponnese. The first caused damages to the entrance and façade of a central bank of Kalamata, the region's capital, while the second erupted a hundred kilometers from the city, in the archaeological site of Mystras, destroying parts of the statue of Constantine Palaeologus, last emperor of the Eastern Roman Empire, more commonly called 
Byzantium among Greeks. Five men, among the ages of 25 and 52, residents of small towns ranging from the Peloponnese in the South of the country to Macedonia, the northernmost Greek region, were arrested under charges rated as felonies: arson, terrorism, armed band, etc. The charges read that the team, whose ideological fermentation had lasted for 6 years as they immediately confessed, had conspired for these and many more terrorist attacks in order to "blow up half of Kalamata" and, according to their own view, "liberate Greece from the New World Order".

A rich arsenal, comprising AK-47s, grenades, bows and arrows, many guns and massive quantities of TNT were found in the homes of two of those accused of taking part in this conspiracy. The arrested claimed that their organization, called “Omada Epsilon" (Epsilon Team), aim to "take down the conspiracy inflicted on Greece by the banks and by Orthodox Christianity”. Writings on the Epsilon that I was familiar with claimed, among other details, that the group has fought against Jews since the dawn of time. The Kalamata contemporary Epsilons professed themselves as pagans, followers of the ancient Greek gods, and claimed they shall continue their political and military endeavor. Most importantly, they referred to the Epsilon as a positive conspiracy for the future of a truly free Greece. The sign of the Epsilon, quite known and recognizable by many Greeks, was sprayed close to the sites of the bombings. That recognizability, allegedly, led to the arrests of those claiming to serve the Epsilon cause.

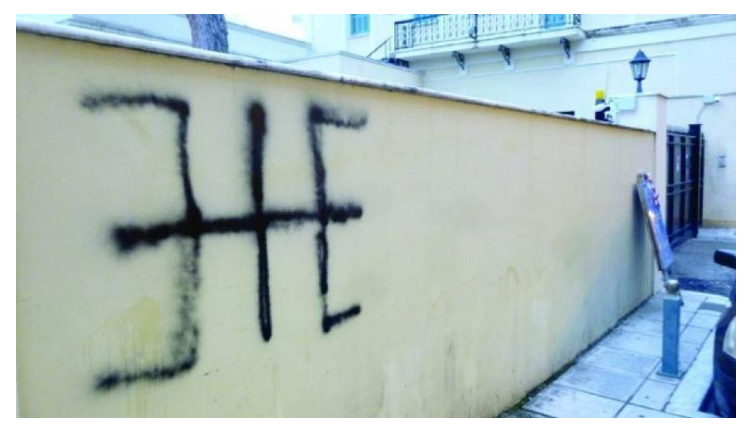


The Delphic double "E", sprayed outside the Kalamata bank, is a recognized symbol of the "Epsilons". Source: www. Mynews.gr

That same October day, another interesting arrest occurred. Artemis Sorras, a 55-year old man that emigrated back to his native Greece from the US, was detained by the Rhodes police. After residing in the US for ages, presumably living in riches, he claimed he returned in order to "save the country" with the outbreak of the crisis in 2010. In a visit to the island to promote his political agenda he was joined by about one hundred supporters, and delivered a firebrand speech, "accusing" a local reporter of being "a mason and a Jew".

Sorras was arrested the next day on criminal charges of defamation, although it has not been established why exactly these "accusations" are defaming someone. He entered a process of propagating he could save the country and enjoyed quite some visibility. His political rally is premised on one practice, him donating $600 \mathrm{bn}$ Euros to "the Greeks" (no mention of the Hellenic Central Bank), "if allowed by the masonic, Jew-seeded politicians". This money was the main bulk of the famous katapistevmata (trusts), funds that Sorras allegedly credited for free in the name of the Greek people - but not their (over-indebted) sovereign state.

I witnessed an open speech by Sorras, in a square in an Athens suburb when I was doing fieldwork for previous research. Sorras, who argues to have a fortune of 2,8 trillion $€$, claimed in that speech, that he and his 'movement' could inspire the solution of the debt problem of Greece. That speech was given before the January 2015 elections (that brought "left-wing" SYRIZA to power) and, back then, Sorras would still claim that the Epsilon helped him amass this great pile of wealth. He insinuated that his money was raised in part by the Epsilon group conspiring for 
decades for the nation's wellbeing in America - and possibly for millennia in other parts of the world. Maintaining these liaisons, Sorras managed to sell the apocryphal technological knowhow of "the Ancient Greeks" to President Obama. His patent on spacecraft technology really impressed Obama, who ordered the ample pay to Sorras' account. The details of the negotiations and the agreement Sorras and Obama reached remain a secret, which serves as the mystic premise of his hidden, immense wealth.

Sorras' political vision has not changed since 2011, when he first rose to prominence, as he always insists in owning that tremendous amount of money and always reminds the audience that he wants to donate some of it to his country, when and if- given the opportunity. Since 2011, he has spoken in prime-time TV on several occasions, and has recently, especially since mid-2016, organized his movement (Ellinon Synelefsis, "Assembly of the Greeks") across the country. Sorras denies being an Epsilon today, but he does claim he is close to "these circles" and indeed a few years ago, when the Epsilon idea was at its most popular. The Ellinon Synelefsis operates as a, by now (early 2017) very vast network of assemblies, with 200 office branches around Greece, and soon to arise as a political party, anticipated to enter Parliament in the coming elections.

Apart from getting to know Sorras in person, I have also been lucky to meet and spend one year of intense and deep talks with the person who created the "Epsilon" cosmology, Aris Dovlis, a 49-year old author from Thessaloniki. A prolific writer and visionary with around 40 books on his back, and a most influential figure in Greek public discourse on "alternative" or "strange" knowledge, Dovlis shared a lot of insights with me on the makings of both the intellectual genealogy of the Epsilon idea and praxis and on the group that put the Messinia bombs as well. Dovlis had also met and discussed with Sorras several times over the years (they met in 
2000). Sorras was a self-proclaimed member of the Epsilons, Dovlis thought; he did not think highly of this "ambitious crook". He told me that Sorras was a "paranoid man", who was using these claims to money in order to get access to the money of his group's members. Indeed, all of the 200 branches and the hundreds of new members of the Sorras' Ellinon Synelefsis movement were operating on member donations, that encouraged multi-level marketing. The mythical wealth fund of the trillioner ended up operating ostensibly as something resembling a pyramid scheme. Exponents and sympathisers of this scheme were generally branding this type of wealth as morally "good" and positive. Not all types of ways to conceptualise wealth were moralized this way, however.

\section{Bad wealth, good wealth: Anti-semitism}

The anti-Semitism of Sorras' statements alludes to the long history of conspirational thought regarding "immoral" wealth and secretive power, that conspiracy theorists struggle and engage with. Fascinated with the potential of hidden wealth and suspicious of "other" bearers of wealth, conspiracy theorists in Greece have often scapegoated marginal groups. Freemasons and Jews are the constant aim of their concerns, precisely because of a historical assumption that they had made fortunes out of conspiracy and usury.

Interestingly, associating Jews with debt and indebtedness has formulated much of this imagination, leading to a history of discrimination across most places Jews ever lived (Graeber 2011: 288-289). In fact, Jews in the late Middle Ages were actually surrogates of usury, abused by their lord bosses (Graeber 2011: 11). This strand of bigotry towards Jews and Freemasons (often the two categories collapsing 
into each other) has historical roots almost everywhere Jews have lived, and certainly was an oft phenomenon among Greek conspiracy theorists; however, not all shared this view.

Spending time on social media by following the web-links my interlocutors uploaded, I was amazed to find that Giorgos Zinos, one of the main two publishers of Antiquity's Classics in Greece, had a tendency to upload articles on his Facebook page about Epsilon and similar conspiracies. I approached him and, although reluctant, he eventually became an important informant. An owner of a half-defunct bookstore in central Thessaloniki, he made a constant income through the University's subscribed book list from his store, bought with state subsidies and distributed to Philosophy and Classics students for free.

He lamented (like most other informants-bookstore owners) that the Internet had done much wrong "to their field". He had wanted to expand in conspiracy theory books himself but never did, due to the proliferation of information on the web, which had diminished selling expectations. Departing from a hope he would have some sympathy to the inspiring and tragic story of the Salonica Jewry (see Mazower 2005, esp. 421-442), I explicitly asked him why his Facebook statuses sometimes expressed suspicion for Jews as a wealth and power-obsessed people. He responded that Sorras and the Epsilons linked over a good kind of wealth, money set out to cater for Greeks. This fund was geared towards Greeks only, and was accountable to them only (rather than the Greek state). He also alluded to a different kind of wealth, bearers of which, "especially in the past", had been "the Jews". Zinos and other publishers in that trade of alternative facts sympathized with the possibility of a wealth fund geared towards "liberation", a positive conspiracy, accountable to "real Greeks". 
Zinos' publishing house is widely considered to be the utmost authority in the Classics genre. If Reason is rooted and stems from the Classics, and the latter's most integrated publication is hosted by exponents of the Protocols of the Elders of Zion, then the paranoia of the Protocols is well placed within a context of reason, one drawing from the epistemic foundations of Western instituted knowledge. It is rationalized by association. This reading of the textual material is important to measure its degree of paranoia; after all, the everyday world is not in the text but encompasses and yields its force to the text (Kapferer 2012: xvii). As Zinos told me, "truth and reality are as far between them as the book and the world it describes".

\section{Protocolling a History of Hate}

The Protocols of the Elders of Zion is a conspiratorial classic; it postulates that Jews are amassing wealth and power and are conspiring for world domination. It is "the Bible, or rather, the anti-Bible", as a young reader told me in Aristotelion, another bookstore in which I spent a fair bit of my fieldwork. First published in 1903 and now one of the best-selling books of the $20^{\text {th }}$ century, it could be stated with reason that it is indeed a Bible of anti-Semitism and of classic conspiracy theory. Adolph Hitler loved the book - and so do millions of readers across the contemporary world, as it still sells, in various translations, although it is banned in some countries. It is written in somehow prophetic and mystic, conspiratorial language, and poses as a leaked document - one that was meant to only circulate between "Jews". It is laden with advice as to how the "Jewry" can make use of their wealth and influence in order to infiltrate and manipulate governments and institutions across the world, aiming for some sort of international Zionism. It postulates, by association, and as suggested explicitly in one classic introduction, written by a French fascist, that Jews are meant to 
act as cold bearers of business, keepers of Masonry, believers in a Money-God, and amassing gold to achieve great influence.

The Greek latest edition (2003), as well as almost all editions that preceded and followed it, is based on the classic 1932 translation from the French (Taguieff 2006). That text, in its turn, was the translation of a document written in Russian by the Ochrana, the secret police of the Czar, in the late 1890s. Those who wrote it claimed it was written in Hebrew, and this idea stuck -and is still shared by conspiracists across the world.

I first encountered this latest publication of the book at the Aristotelion bookshop, located 50m from the centremost square of the city, the defining Aristotle square, is a renowned spot for alternative sources of knowledge or for "the routes the system would not take" as the owner, Mr. Voios, told me once. In his mid-50s, he shared the place with a friend of his. Aristotelion was located in a huge basement and was privileged with a spacey area for socialization (complete with four chairs, a table with the perpetual frappè on it and most often, a guy or two speaking in low voice over a book). Once a week, I would join them in their weekly event, an invited speech on issues pertaining to alternative paths to Greek nationalism, irredentism or revisions of certain dark corners of Greek history, including tracing lost wealth. Their political affiliation was far removed from the Golden Dawn ${ }^{3}$, and while one central figure (and everyday visitor to the bookstore) would identify his stance with "conservatism", theirs was a mostly intellectual, even elitist endeavour. They had their own publishing house, with an attention to and a fascination for secret, wealthy and powerful brotherhoods. The Illuminati was there, surely; but most definitely the Knights Templar was their primary focus of interest. The imprint of the Knights in Rhodes and Cyprus was 
too huge to ignore both for a revived islamophobia among Greeks and for the immense wealth, allegedly treasured and hidden in those islands.

The Protocols of the Elders of Zion was most ubiquitously prominent among other "history" books in Aristotelion. The book has an interesting history in itself in Greece. It has had dozens of different publications, a number unprecedented in any other country in Europe, according to the documentation available. At the time of writing, 10 different versions of the book are in circulation in the Greek market, most variations of a 1932 translation (Psarras 2013: 11).

1932 is the year that Salonica saw the first fascist movement in Greek history, the anti-Semitic terrorist organization EEE. The organization, importantly, introduced both a modern-type of anti-Semitism in Greece, at the same time they introduced the idea of "Epsilon" as political agency (EEE means Three Epsilons), Epsilon here standing for Ellinas (Greek). All this, expectedly, took place in the early-1930s (Mazower 2005: 413-414). During the course of fieldwork, I purchased five different editions of the book from places as diverse as central high-street bookstores to small bazaars of second-hand book markets. I purchased what is most probably the most authoritative one, a 2003 edition from Aktis ${ }^{4}$, in the Thessaloniki book fair of June 2015. While spending much time flipping the pages over the counter, allegedly -and unwittingly- with a raised eyebrow, a young seller approached me. He stated, with much confidence, that "this was the best source that I could find when seeking the truth".

I recognized a familiar face, Kostas, the 25-year-old younger son of a wellknown bookseller of central Thessaloniki who had been involved in both socialist and, afterwards, nationalist politics. The bookstore, located about $150 \mathrm{~m}$ from Aristo- 
telion, but literally on Aristotle square, was one of the three most significant in the city throughout the 1980s and 1990s, but had faced bankruptcy and closed down in 2012. Towards the end of their career, the Tellidis bookstore had their own editions and published a series of books much alike the Aristotelion's interest, including some Epsilon philology.

It came as no surprise though that "the best" was the Protocols, so I inquired further as to what Kostas meant. We started chatting and he explained with passion that "this was unrelated to what people call conspiracy theory as it was most obviously a set of analytical, truthful facts". I asked about the text's translation, which puzzled him.

He then referred to his mother, a classy woman in her 50s, of the city center's distinct bourgeoisie. She took over the conversation and explained that the book was a direct translation "from the original Aramaic". Meeting some degree of doubt on my side, she insisted in pointing out the "originality" and "authenticity" of the document, as well as of the translation and of the publication in general. She eventually underlined how this authenticity reverberated its "truth", and urged me to flip the pages and open in a random spot. When I inquired why, she pointed out that the book's freshness resonates in our current perceptions of the financial crisis, despite it was written in a bygone age. Everything you can imagine of the crisis, you could spot it in it, as her son added. She repeated similar words when I encountered her again some months after, in a friendly visit she made to Aristotelion and in fact inquired as to whether and to what extent I had now "understood the truth about the crisis".

This textuality of intolerance, basing anti-Semitism on an "authentic" text, is not to be taken lightly, especially as it is contextualized in a ritualized accord of au- 
thenticity and truthfulness when, supposedly, accounting for a history of wealthamassing and conspiring Jews. This intolerance confirms the centrality of antiSemitism in some conspiracy theories (Aaronovitch 2011). But one would doubt an inherent irrationality here. I would like to point out two facts that might point to a direction of putting the text and its readings in a wider context of paranoia within reason (Marcus 2003).

Firstly, the translation's factuality: Kostas's and his mother's information were, in this case, factually wrong. As we saw, the book was written in Russian and posed as a Hebrew text. Thus, in this chain of cultural mis-translation, we encounter a series of factual and mythical linguistic conversions of a faux text: from Greek back to an imagined Aramaic, to French, to Russian and Hebrew. The originally claimed text is five languages removed from the Greek translation, in the 2003 book I am quoting from in this essay. The cultural and imaginative gaps in this genealogy of ideas, however, are consistent with the conspiratorial truth it evokes. This trans-cultural distance does not threaten the internal logic of conspiracism; with the mythical time claimed in this textual dimension, it is perhaps reinforced. In fact, this distance from the actual fact might be a source of allure for its relevance. This reading of the textual material is important to measure its degree of paranoia; after all, the everyday world is not in the text but encompasses and yields its force to the text (Kapferer 2012: xvii).

There are different levels of inconsistency-spotting that are not about comparisons across different orders of understanding and appreciating "reality" but about cracks within the same truth-sphere that conspiracists claim as a field of expertise. While it is redundant to reduce inquiry to spotting incoherencies in conspirational narratives, I find it is important here to underscore the textuality's clashes and conver- 
gences with the real world, precisely to draw attention to their sense of distance of truth from reality, a marked setting of distinction of their mode of thinking.

This plays out in two horizons. The first is synchronic; it concerns the contemporary, crisis-inflicted, perceptions of the Protocols and their anti-establishment, anti-wealth critique, as well as the actual contextualization of the book in the genealogy of rationalism, alongside the Classics. This opens up a prism to the second horizon, a historical one: the text is placed in a combinational, unique and selective temporality that can take factual leaps as well as synchronize perceptions past.

The idea that stems from readings of the book, according to my interlocutors, is that this assumed past wealth circulating among "Jews" (wealth that is now distant and lost, although present among some "Jews", such as the Rothschilds) could play a fundamental role in shaping world government. In this way, the text stands between a self-fulfilling prophecy on an eerie globalisation and an implicit anti-establishment critique of it. The idea that wealth can buy out governments and that circulating wealth, mystic and secretive, distant from the masses, can shape a "world government" is something that one can stumble upon in YouTube, social media or online newspaper commentary. It is a vox populi with quite some currency, still.

The internal logic of conspiracist takes on wealth lies precisely there. Their worldview ascribes coherence on the fragmentation of the practical world (Ingold 2007; Kapferer 2012: xxx). We can approach this, drawing on precisely the "common sense' mytho-logics (Kapferer 2011: 17) of modernity, currently rampant in crisisridden, financially damaged Greece. It is the mythologic, yet cohesive "truth", rather than the inconveniently fragmented "reality" that inspires conspiracists - which is why I choose to call their endeavor "truth activism". As Geertz says, the only narra- 
tives that are fully coherent are those of the mentally impaired (1973). In this distance, money that seem to be distant is reinforced as wealth - in a sense of hidden treasure. Sorras' money, like truth ${ }^{5}$, acquires a mystical and mythical allure, as it is situated afar from reality.

While publishers make some money disseminating conspiracy theories however, the flow of wealth on the other side of the conspiracy canon is less impressive and could be associated with shame over the way people (have to) make a living through associating themselves with conspiracism. Maria, for instance, is a 32-yearold woman who worked for the Edros publishers, one of the most successful houses of the genre. Coming from a left-wing background (her father, who had passed away recently, was a committed unionist), she found herself in need of employment. She now enjoys the fact that she can have maternity leave from Edros ("as well as a steady pay"), but often thinks "what my father would say" with degrees of shame. "Just to think of his struggles, as well as those of my grandad, who was in the Resistance, you know... it is really weird that I work in this environment here, alongside such ideas".

Maria works as a salesperson, managing internet and phone orders and house delivery of the Edros books. She stressed that the vast majority of readers are pensioned men, usually very old, that have had a rightist background and in most cases live in precarity and poverty. The books they order praise Putin, glorify the "prophecies" of Orthodox monks with jingoist rhetoric, and insinuate a history of ancient creed for Greeks. Some of these books claim hidden wealth and power, associated with Epsilons. Maria, unconvinced and even inimical towards these ideas, underlined to me an almost ontological distance she feels from this world: "Cos they live in their own world. There is a thing they live in, which is their reality. And then 
there is their obsession with the truth. How they reconcile that truth and that reality, I don't know".

She described the readership of these books as people living in a materially difficult condition, lacking any kind of social privilege. "These people are incredibly uneducated", she notes; in one occasion, she narrated to me with a mixture of contempt and compassion, an old man called her to complain about how he had not ordered a book called "Delivery Charges", although it was stated (and charged $3 €$ ) in his receipt. Stamos, the delivery person, explained to me how he had encountered people literally counting their pay coin-to-coin with a sense of shame on their doorstep. "That guy literally did not have those 3 euros - and of course had no idea about what this charge meant".

Seeking out the distance between truth and reality for conspiracists, as well as their relation to material assets and especially with wealth, I looked out for Edros' owner, the well-known Vasilis Vaiopoulos, a man with a rich biography, which included 4 years in Parliament with a (now quasi-defunct) right wing party. I met him at his office at Energy radio, where Vasilis was busy and, after a wait of an hour and a half, only met me for 45 minutes. He apologized when he said "I have to chunk you out as I need to make payments". I told him about the good conditions of the Edros' employees. He boasted that it's the same for his Radio staff, as "I have 25 people working here - I feed the mouths of many a young people". Sat in front of a caricature of his as well as an "original” emblem from the Greek Revolution of 1821, about to launch a new (Putinist) political party, he was in high spirits.

There is a difference between reality and truth. When I read and write history, I register (katagrafo) reality, not truth. My truth might be different from yours. 
But reality is reality. The sun is the sun. A table is a table. The truth is that you can say 'this table is nice, but I don't like it very much' [...] there exist many, different truths. While reality is one. And it's not only factual but also theoretical; that is, you cannot prove that the Earth is rotating; it's just scientific reality. (Vaiopoulos, italics added to denote emphasis in speech)

The idea of truth is central here. It figures as the constitutive element in structuring conspiratorial pursuits. It also is different, in the words of conspirators, from "reality". In another interview close to that date, he said:

An author mainly writes from his soul, while a researcher mainly from the mind. I write mainly from the soul, from the heart, but with facts. I am doing the research and expose the facts in order to demonstrate and prove that those things I believe in are indeed how things are. And the other, the reader, has the burden of proof. When I have a sense of the truth, I go out in books to find it, until I've found it. (Vaiopoulos, italics added).

The dazzling point on finding the truth here, is unwittingly repeated as a resonance of a classic quote from Mein Kampf, where the truth-tamed reality is set up on a reversed burden of proof (see Psarras 2013: 53-54). That is, "it is not I who need to explain and prove; the plain fact that power is afraid of what I am saying and tries to disapprove it, implies I am right".

Dovlis, far from a fascist, called this sense of reality "the elephant and the poppy", in an interview to me. "-There is an elephant hiding behind every poppy, runs the syllogism, do you see it? -No. -Well, see how well he's hiding?" However, when I questioned the tactics of people like Vaiopoulos or Liakopoulos, another conspiracist 
of the extreme far-right, Dovlis claimed: "they are just selling books, not guns; it's a peaceful way to make some money".

\section{"Not that crazy": conspiracy, accountability, tollerance}

The soothing statement just above needs to be taken seriously, as it shows the analytical limitations in fully identifying conspiracism, seen as truth-activism, with the dangerous far-right. While Nazis had an ambivalent relationship with truth ("truth is the enemy of the state", wrote Goebbels infamously), the veil of reality, in classical conspiracism, lies in front of truth. "Look behind what you see, the truth is behind", as Vaiopoulos told me repeatedly.

The evidence of this research itself does not point to the direction of the farright stereotypes as discussed in the relevant literature. Rather, authors have often underlined how anti-Semitism or anti-Masonry are futile pursuits,

I do not see why I should hate the Jews. Last time my nation fought against the Jewry was at 1000BC. All those out there with anti-Semitic feelings, I would suggest a dose of medicine. (Vaiopoulos, June 2015).

This tolerance often extends to the other arch-enemy of paranoid conspiracism, Freemasonry.

[other authors] claim that the Freemasons are the root of all evil. There is nothing sillier than that. My collaboration with them has been ideal and I have come to know them from inside. My own publisher is a $33^{\text {rd }}$ degree Mason. There is nothing bad about this at all (Monkakis, 75). 
Monkakis' publisher owns a bookstore that is Thessaloniki's central point of conspiracism. The store is indeed located opposite the main Masonic Lodge of Thessaloniki, in a bloc that also hosts one of the most majestic and high-cultured cinemas of the city, Voreion. One wonders about the heart of interest of conspiracism, should the two pillars of "paranoid" rightist thinking, associated to mythic, obscure, unaccountable wealth (anti-Semitism and anti-Masonry) wither away. In this mosaic of ideologies, composed of disparate voices, the real common denominator is a generally understood "truth-activism", a hunt for the truth "out there", in the weirdest of places. In my informants' confessions, there is a cognitive gap between:

"Here and there, the place where we are and the place we are going to... The journey itself, the trip of knowing, of getting to know, is widening the gap. Before Amundsen went to the Pole, the Pole did exist - but not in the mind of the many. Researching is trying to fill the gap - which is always widening" (Aris Dovlis)

This problematic on the distance between reality and truth is coupled with the idea of distant wealth. For the moment, resituating the discussion so far within the context of the crisis and its situated rationalities is at play.

The idea of hyperrationality (Sampson 2010) is rooted in conspirational claims to and juxtapositions with epistemic knowledge. Mixing legend and myth, conspiracists over-rationalise symbols and over-think actual reality (Fritze 2009: 15). In the light of a breach in historical understanding, as the $9 / 11$ and its cognitive aftermath have been 
for the West, and the crisis has been for Greeks (Knight 2015: 3) conspiracists are stirring clear of non-critical analyses. But while they are willing to engage with critical readings of the past regarding wealth "agents", some are also prone to support current wealth "agents", such as Sorras, uncritically.

Instead of aloof suspicion, we might be facing a selectively critical investigation of processes "hidden" from us. The core of the counterclaim to transparency and accountability lie on a conspiracist belief in secrecy, including mystic, hidden wealth that might have redemptive powers (cf. Zucman 2015) The cognitive gap common to suspicious thinking has moved from reductive to inductive reasoning (Pantazopoulos 2015: 21-22).

I am here uninterested in "exposing" a factual lapsus, as to whether the Epsilon or Sorras' wealth "exist or not". That is, the pragmatics of an interlocution are scrutinized in terms of the interlocutor's interest itself. What is more, it is important to underscore that while most conspiracists adhere to some fundamentals, including "International Zionism" for instance, their views about the cosmological ramifications of this "reality" are not only different, but richly diverse.

\section{Transparency and conspiracy: some wealth is better than others}

Anthropological works stress the idea of "a culture of suspicion", although the discipline is also cautious to draw a line on the idea of paranoia. At once ahistorical and anti-historical, conspiracy theory is rooted in an organized sense of resisting the capitalist "New World Order" (Sanders and West 2003). As George Marcus pointed out, however, the very situatedness of that "paranoia" sits comfortably in our broader 
structures of reason ${ }^{6}$ (2002) and thus what can be mainstream capitalist trends, including hiding money away, beyond the taxing gaze of the state.

In fact, claims to transparency in an era of actual opaqueness of power can breed conspiracism. Transparency must be framed in terms of rationalization within democracy and its morality - but secrecy and conspiracy follow from it (Marcus and Powell 2003: 330). This way, conspiracy theory rises as a doubting mechanism, the offspring of contemporary "clean", audited political regimes, based on accountability and of political debunking of secrecy - in the case shown below, in terms of antiSemitism. Everything is in the open, the liberal consensus argument goes, although critiques to contemporary capitalism prove that it is not (Piketty 2013; Shaxson 2015). But conspiracy theorists in Greece, while tapping into anti-Semitic historical narratives about the hidden wealth of Jews, sometimes argue that positive wealth can be hidden as well - and there is no reason to account for it.

Marcus' phrase "paranoia within reason" partly implies that paranoia emerges, at times, within practices and constructions of reason and rationality themselves (Marcus and Powell 2003: 331). The comparison between the rationality of conspiracism (associated with "paranoia") and the magic of markets in crisis (associated with "rationality") is surprisingly twofold and operating on two fronts.

On the one hand, seeing conspiracy outside the framing of "paranoia" does not imply rationalist calculative actors that strategize their moves. We should aim to deeconomize conspiracism as a response to a crisis-world, and appreciate it as a cosmology in its own right, one that shaped the current systemic and anti-systemic responses to crises (as in Bakalaki 2016). On the other hand, we witness the constitutive power of conspiracies: their dissemination contributes to bottom-up build of bankruns and has major financial impacts. The world of economic rationality appears less 
based in evidence and accountability, and more driven by numerically shaped, magicinspired speculation.

So what happens when an anti-establishment, positive wealth promise enters the public sphere? How are we to account for money that are not audited, not accounted for, probably not "clean" in the conventional understanding of accountability and accounting? While the anthropology of accounting is often linked to labour rather than wealth (Bryer 2014), there is room to revisit how conspiracy theory can be reshaped in the light of positive, yet uncounted for, hidden wealth. The notion of accountability for wealth has challenging democratic, liberal consensus with -for instance- recent debates on the Panama papers leaks. Scholarly takes nuance these public concerns, including critiques to arcane, tax-free treasure islands (Shaxson 2015) to calls for centralized authority and cleaner taxation geared towards alleviating equality (Piketty 2013). Fighting the hidden wealth is a current struggle for democracy - but conspiracists seem to thrive in the secrecy surrounding positively geared wealth. Their discursive pursuits aim at adjudicating and rejecting, even eliminating classic anti-Semitism conspiracies. But, when it comes to accounting for wealth, conspiracists can construct "truth" without referring much to accountability; or by being selective about it. Thus, Sorras' money could be good wealth, while the assumed wealth of "Jews" can be badly moralized wealth.

Immense wealth, when it comes to save the day, can be seen less critically than historical, alleged wealth. The potential wealth of Sorras, the unexpected trillionaire, portrays an alternative sovereign body to that of the state. It is an alternative fact that claims its own space for political legitimacy, based on an assumed wealth fund. Accountability is associated with democracy and a sense of being responsible towards instituted social life, in the form of the democratic state. This 
might be particularly salient in a place like Greece, where the sovereignty of the state itself has been disputed, as per an indebted sovereign amidst deep crisis and recession.

\section{Funding acknowledgment}

The research leading to this essay was partly carried out in relation to and supported by the ERC Advanced Grant project "Egalitarianism: Forms, Processes, Comparisons" (project code 340673) running from 2014 to 2019 and led by Bruce Kapferer at the University of Bergen.

\section{References}

Aaronovitch, David. 2011. Voodoo histories: The role of the conspiracy theory in shaping modern history. New York: Riverhead books.

Aupers Stef. 2012. 'Trust no one': Modernization, paranoia and conspiracy culture. European Journal of Communication, 27: 22-34.

Bryer, Alice. 2014. Participation in budgeting: A critical anthropological approach. Accounting, Organizations and Society, 39(7): 511-530.

Bakalaki, Alexandra. 2016. Chemtrails, crisis and loss in an interconnected world. Visual Anthropology, 32(1): 12-23.

Evans-Pritchard, E.E. 1976. Witchcraft, Oracles and Magic Among the Azande. Oxford University Press.

Fritze, Ronald. 2009. Invented Knowledge: False history, fake science and pseudoreligions. London: Reaktion Books. 
Geertz, Clifford. 1973. The Interpretation of Cultures: Selected Essays. New York: Basic Books.

Graeber, David. 2007. Possibilities: Essays on Hierarchy, Rebellion, and Desire. London: AK Press.

Graeber, David. 2011. Debt: The first 5000 years. New York: Melville.

Graeber, David. 2015. Radical alterity is just another word for saying "reality": A reply to Eduardo Viveiros de Castro. HAU: Journal of Ethnographic Theory, 5(2): 1-41.

Hofstadter, Richard. 2008 (1952). The paranoid style in American politics and other essays. New York: Vintage books.

Ingold, Tim. 2007. Lines: A brief history. London: Routledge.

Kalantzis, Konstantinos. 2015. "Fak Germani”: Materialities of Nationhood and Transgression in the Greek Crisis. Comparative Studies in Society and History, 57(4): 1037-1069.

Kapferer, Bruce 2003. Sorcery, modernity and the constitutive imaginary: Hybridising continuities. Social Analysis: The International Journal of Social and Cultural Practice. 46(3): 105-128.

Kapferer, Bruce 2012. Legends of people, myths of state. Violence, Intolerance and political culture in Sri Lanka and Australia. New York and Oxford: Berghahn Books.

Latour, Bruno. 2004. Why has critique run out of steam? From matters of fact to matters of concern. Critical Inquiry 30(2), 225-248.

Marcus, George. 2003. Paranoia within Reason: A casebook on conspiracy as explanation. Chicago: University of Chicago Press. 
Mazower, Mark. 2005. Salonica: City of ghosts.

Pantazopoulos, Andreas. 2015. Resistant conspiracy theory. In: Taguieff, PierreAndré. 2015. Conspirational thinking and "theories of conspiracy". Athens: Epikentro.

Psarras Dimitris. 2013. The best seller of hatred: The protocols of the Elders of Zion in Greece, 1920-2013. Athens: Polis.

Pelkmans, Mathijs and Rhys Machold. 2011. Conspiracy theories and their truth trajectories. Focaal-Journal of Global and Historical Anthropology 59: 6680.

Sampson, Steven. 2010. Truthers: the 9/11 truth movement and the culture of conspiracy. Paper at the American Anthropology Association Annual Conference.

Sanders, Todd and Harry West (eds). 2003. Transparency and conspiracy: Ethnographies of suspicion in the New World Order. Durham: Duke University Press.

Shaxson, Nicholas. 2015. Treasure islands: Tax havens and the men who stole the world. London: Bodley Head.

Sutton, David. 2003. 'Poked by the 'foreign finger' in Greece: Conspiracy theory or the hermeneutics of suspicion"? In: Brown, Keith and Yannis Hamilakis (eds.) The usable past: Greek metahistories. Lanham: Lexington Books, 191210.

Taguieff, Pierre-André. 2010. Conspiracy theories: Esoterism, extremism. Athens: Polis.

Taguieff, Pierre-André. 2015. Conspirational thinking and "theories of conspiracy". Athens: Epikentro. 
Waters, Tony and Dagmar Waters. 2015. Weber's rationalism and modern society: New translations on politics, bureaucracy, and social stratification. Palgrave MacMillan.

Zucman, Gabriel. 2015. The Hidden Wealth of Nations: The scourge of tax havens. Chicago: University of Chicago Press.

${ }^{1}$ Fieldwork took place for 20 months in Thessaloniki, the country's second largest city.

${ }^{2}$ Such Greek evidence could be indicative of a popular mistrust to instituted "reason" that is grossly exacerbated by the crisis (Kalantzis 2015). Mistrust and suspicion have been repeatedly identified as a sort of cultural work invested in Greeks' perception of history, future and otherness (Herzfeld 2007). Anthropologists often see this Greek conspiracism as a result of unequal power relations (Sutton 2003), the way they see conspiracy theory more generally (Sanders and West 2003). Not reducing conspiracy to paranoia, anthropologists often raise the point that creative and imaginative suspicion is indeed an outcome of Enlightened modern thought (Marcus 2003; Aupers 2012), or that conspiracy itself as a cognitive category is the offspring of power-knowledge relations (Pelkmans and Machold 2013).

3 The Golden Dawn is the renowned organization turned political party that since the 1980s has been operating as a Neo-Nazi formation in Greece. Their appeal since 2010 has been phenomenal: they have skyrocketed to occupying the third place in the country's parliament twice, after the elections of 2012 and 2015, averaging a $6.5 \%$ of the national vote and somehow ostensibly toning down their Nazism onto more conventionally farright discourses.

${ }^{4}$ Aktis has the widest array of publications of Classic Greek texts (more than 700 books in its list) in the world. Like Zitros, the publishing house is widely considered to be the utmost authority in the genre. The house was led, until 
his death in 2014, by an inspiring yet reclusive man who was a fervent conspiracy theorist: he chose to publish, outside the list of the Classics, the Protocols of the Elders of Zion, as well as Hitler's Mein Kampf.

${ }^{5}$ Pelkmans and Machold are concerned principally with how truth and untruth are produced in such asymmetrical fields of power: for them, while some conspiracy theories are nonsense, others correctly identify secretly colluding powers (2011: 73). We need to interrogate systematically the links between power and truth (2011: 68) in this process, as the classificatory mechanisms of valid knowledge are certainly, to a good extent, products of asymmetrical power plays. The power of labeling has specific normative effects that can render a valid theory obsolete by the classificatory mark of “conspiracy" (Pelkmans and Machold 2011: 74-75). In effect, conspiracy theories are distinguished from "valid", scholarly theories, by mechanisms of epistemic power. This is the source of Pelkmans and Machold's critique to Sanders and West's (2003) generally relativist position that recognizes an inner truthfulness to both the epistemic and the conspiratorial worlds. This is done through a partial recognition of conspiracy as a form of magical thinking, akin to Evans-Pritchard's witchcraft (Sanders and West 2003: 12 and 16; Marcus and Powell 2003: 327).

${ }^{6}$ Pondering on the phenomenon, Latour points out that as social scientists we have struggled to make knowledge situated - and now it is situated in places we feel uncomfortable with (2004). 